\title{
Spectrum and frequency of GJB2 mutations in a cohort of 264 Portuguese nonsyndromic sensorineural hearing loss patients
}

\author{
Tiago Daniel Matos*, Helena Simões-Teixeira*, Helena Caria*,†, Ana Cláudia Gonçalves*, Joana Chora*, \\ Maria do Céu Correia*, Carla Moura ${ }^{\ddagger}$, Helena Rosa ${ }^{\S}$, Luísa Monteiro\#, Assunção O’Neill ${ }^{\mathbb{I}, \wedge}$, Óscar Dias**, \\ Mário Andrea** \& Graça Fialho* \\ *Centre for Biodiversity, Functional, and Integrative Genomics (BioFIG), Faculty of Science, University of Lisbon, Lisboa, Portugal, \\ ${ }_{\dagger}^{\dagger}$ Higher School of Health, Polytechnic Institute of Setúbal, Setúbal, Portugal, ${ }^{\ddagger}$ ORL Service, Medical Genetics Service, Hospital S. João \\ (Centro Hospitalar de São João, E. P. E.), Porto, Portugal, ${ }^{\S}$ ORL Service, Hospital Garcia de Orta, E.P.E., Almada, Portugal, \\ \#ORL Service, Hospital Dona Estefânia (Centro Hospitalar Lisboa Central), Lisboa, Portugal, "IDepartment of Head and Neck, Hospital Egas \\ Moniz (Centro Hospitalar de Lisboa Ocidental, E.P.E.), Lisboa, Portugal, ^Department of Anatomy, Faculty of Medical Sciences, New University \\ of Lisbon, Lisboa, Portugal, and **Department of ORL, Voice and Communication Disorders, Hospital Santa Maria (Centro Hospitalar de Lisboa \\ Norte, E.P.E.), Lisboa, Portugal
}

\begin{abstract}
Objective: To assess the spectrum and prevalence of mutations in the GJB2 gene in Portuguese nonsyndromic sensorineural hearing loss (NSSHL) patients. Design: Sequencing of the coding region, basal promoter, exon 1, and donor splice site of the GJB2 gene; screening for the presence of the two common GJB6 deletions. Study sample: A cohort of 264 Portuguese NSSHL patients. Results: At least one out of 21 different GJB2 variants was identified in $80(30.2 \%)$ of the 264 patients analysed. Two mutant alleles were found in $53(20 \%)$ of these probands, of which $83 \%(44 / 53)$ harboured at least one c.35delG allele. Twenty-seven (10.2\%) of the probands harboured only one mutant allele. Subsequent analysis revealed that the GJB6 deletion $\operatorname{del}(G J B 6-\mathrm{D} 13 \mathrm{~S} 1854)$ was present in at least $7.4 \%$ (2/27) of the patients carrying only one mutant GJB2 allele. Overall, one in five (55/264) of the patients were diagnosed as having DFNB1-related NSSHL, of which the vast majority (53/55) harboured only GJB2 mutations. Conclusions: This study provides clear demonstration that mutations in the GJB2 gene are an important cause of NSSHL in Portugal, thus representing a valuable indicator as regards therapeutical and rehabilitation options, as well as genetic counseling of these patients and their families.
\end{abstract}

Key Words: GJB2; GJB6; DFNB1; connexin 26; hearing loss; hereditary; genetic; deafness; mutation

Hearing loss (HL) is the most common congenital sensory impairment, and the most prevalent sensorineural disorder (Hilgert et al, 2009), being a major public health concern.

Regarding nonsyndromic sensorineural hearing loss (NSSHL), more than 140 genetic loci have been mapped, with more than 60 genes identified to date (Alford, 2011; Smith \& Van Camp, 2011). Despite this extreme genetic heterogeneity, mutations in the GJB2 gene, encoding the protein connexin 26 (Cx26), are a major cause of NSSHL in many world populations, which makes GJB2 the gene most frequently associated with this condition. Two gross deletions, del(GJB6-D13S1830) and $\operatorname{del}(G J B 6-\mathrm{D} 13 S 1854)$, involving the GJB6 gene, which codes for connexin 30 (Cx30), have also been associated with nonsyndromic hearing loss (NSHL) in several cases, often in trans with a GJB2 mutation (del Castillo et al, 2005; Lerer et al, 2001; Pallares et al, 2002). Both genes, GJB2 and GJB6, are localized to chromosome region $13 \mathrm{q} 11$, corresponding to the DFNB1 locus.

About two hundred GJB2 mutations causing nonsyndromic HL have been reported (Stenson et al, 2009), most of them being recessive. A few specific mutations in GJB2 also have been described in families with autosomal dominant HL (Smith et al, 2012). The carrier rate in the general population for a recessive deafness-causing GJB2 mutation is approximately one in 33 (Smith et al, 2013).

The spectrum and the prevalence of GJB2 mutations vary among different populations. The predominant mutations in Europeans, Ashkenazi Jews, East Asians, and Ghanaian population are c.35delG, c.167delT, c.235delC and p.R143W, respectively (Kenneson et al, 2002). A different GJB2 pathogenic mutation, p.W24X, was found to be the predominant one in NSHL cases in India (RamShankar et al, 2003), and in Gypsies (an ethnic group that traces back to the

Correspondence: Graça Fialho, Centre for Biodiversity, Functional, and Integrative Genomics (BioFIG), Faculty of Science, University of Lisbon, Lisboa, Portugal. E-mail: mdfialho@gmail.com 


\begin{tabular}{|ll|}
\hline \multicolumn{2}{|l|}{ Abbreviations } \\
Cx & Connexin \\
HL & Hearing loss \\
NSHL & Nonsyndromic hearing loss \\
NSSHL & Nonsyndromic sensorineural hearing loss \\
PSDM & PCR-mediated site directed mutagenesis \\
RFLP & Restriction fragment length polymorphism \\
SSCP & Single-strand conformational polymorphism \\
\end{tabular}

Indian subcontinent) from Eastern Slovakia (Minárik et al, 2003) and Spain (Álvarez et al, 2005). This mutation was also shown to have a high carrier frequency $(2.4 \%)$ in the Indian population (RamShankar et al, 2003), and in some subpopulations of Gypsies (Minárik et al, 2003; Álvarez et al, 2005).

Due to the high frequency of GJB2 mutations among NSHL cases in several populations worldwide, mutation analysis of this gene is a widely available genetic test, representing the first step in the molecular diagnosis of this pathology.

Since most GJB2 mutations described so far localize to the coding region (totally included within exon 2), only this region has been systematically analysed. Nonetheless, a few noncoding pathogenic mutations have already been identified, contributing to the elucidation of the genetic etiology of the HL in some patients who harboured only one recessive mutation in the GJB2 coding region (Denoyelle et al, 1999; Mani et al, 2009; Matos et al, 2007).

We present here a comprehensive molecular analysis of the GJB2 gene in a cohort of 264 Portuguese NSSHL patients.

\section{Materials and Methods}

\section{Patients}

A total of 264 Portuguese unrelated individuals (sporadic and familial cases), presenting with bilateral mild to profound NSSHL were tested for the presence of mutations in the DFNB1 locus. They had been referred over the last ten years, from various otolaryngology departments and genetic units, and come from different regions of the country. A recessive mode of inheritance was predominantly observed in the familial cases.

Diagnosis of NSSHL was established by accepted clinical criteria. Infection, oto-trauma, or neonatal diseases causing acquired deafness were excluded by collecting detailed clinical history. Individuals referred as not having been born in Portugal were also not considered.

Written informed consent was obtained from all the participants, or from parents in case of those younger than 18 years.

\section{Audiological methods}

All patients involved in the study underwent otoscopic and audiometric examinations by using age-appropriate methods. Pure-tone audiometry, tympanometry and auditory brainstem response were obtained in a sound-proof room according to current clinical standards. We were not able to retrieve medical history and audiometric records for all the patients. For some patients family histories were unknown.

\section{Molecular analysis}

Blood samples were obtained from most subjects. DNA extraction from whole blood has been performed since the beginning of the study using either Quiagen or JetQuick DNA extraction kits. For some patients DNA was extracted from buccal swabs using the Chelex method.

All DNA samples were first screened for the c.35delG mutation by PCR-mediated site-directed mutagenesis (PSDM) followed by restriction fragment length polymorphism (RFLP) analysis (Storm et al, 1999).

The c.35delG homozygotes were diagnosed as having GJB2related HL and, consequently, no other studies were performed.

Initially, the c.35delG heterozygotes and the negative cases had been screened by single-strand conformational polymorphism (SSCP) analysis, according to Scott et al (1998), followed by sequencing of the relevant GJB2 fragment. In more recent years, all new cases falling into the two above mentioned situations have instead been analysed by direct sequencing of the entire coding region and flanking acceptor splice site, as previously described (Matos et al, 2010). Those c.35delG heterozygotes first analysed by SSCP and in which no second variant had been identified, as well as 29 of the 105 c. 35 delG negative cases which revealed no changes in the subsequent SSCP analysis, were further sequenced for the entire coding region and flanking acceptor splice site.

If the cause of deafness remained non-elucidated, the patients were then screened for the $\operatorname{del}(G J B 6-\mathrm{D} 13 \mathrm{~S} 1830)$ and $\operatorname{del}(G J B 6-$ D13S1854) GJB6 deletions using multiplex PCR, as described in the literature (del Castillo FJ et al, 2005). Twelve cases could not be analysed for any of the GJB6 deletions (eight cases negative for $G J B 2$ mutations plus four c.35delG heterozygotes), and two cases (both negative for GJB2 mutations) could only be screened for del(GJB6-D13S1830), since the corresponding DNAs had meanwhile run out, or had degraded, especially those DNAs extracted from buccal swabs.

Ninety patients among those found not to harbour any GJB6 deletion have been screened by sequencing for mutations in the GJB2 basal promoter, exon 1 and donor splice site. Results concerning 83 of these 90 patients have been reported (Matos et al, 2007, 2008, 2010, 2011).

\section{Results}

At least one out of 21 different GJB2 variants (18 coding and three noncoding) was found in $80(30.2 \%)$ of the 264 patients representing a total of 133/528 (25\%) mutated alleles (see Table 1). All the variants here identified were previously described, with the exception of the novel variant c. $24 \mathrm{G}>\mathrm{A}$, which results in a silent mutation at protein level (p.T8T). Two of the reported mutations (c.-259C $>\mathrm{T}$ and p.M163L), listed in Table 1, were first identified in Portuguese patients (Matos et al, 2008, 2007) included in the sample under analysis. As expected, c.35delG was the mutation most frequently found amongst the NSSHL patients, being present in 84 of the 528 chromosomes analysed, which corresponds to a prevalence of $15.9 \%$ (see Table 1) and a frequency of $63 \%$ of all mutated alleles.

Table 2 shows the frequencies of GJB2 genotypes identified in a total of 264 individuals presenting with bilateral NSSHL. Fiftythree probands (20\%) harboured two GJB2 mutations, of which $83 \%$ (44/53) harboured at least one c.35delG allele. The most prevalent mutated genotype was $[\mathrm{c} .35 \mathrm{delG}]+[\mathrm{c} .35 \mathrm{delG}]$, accounting for $52.8 \%(28 / 53)$ of the individuals with two GJB2 mutations. Next to this genotype, $[\mathrm{c} .35 \mathrm{delG}]+[\mathrm{p} . \mathrm{E} 47 \mathrm{X}],[\mathrm{c} .35 \mathrm{delG}]+[\mathrm{p}$. $\mathrm{W} 172 \mathrm{X}]$, and [c.35delG]+[p.V37I] genotypes were the most represented among patients with two GJB2 mutations (respectively $5.7 \%, 5.7 \%$, and $3.8 \%$ ). 
Table 1. Frequency of GJB2 variant alleles $(n=528$ chromosomes).

\begin{tabular}{|c|c|c|c|c|c|}
\hline \multicolumn{2}{|l|}{ Variant } & \multirow[b]{2}{*}{ Location } & \multirow{2}{*}{\multicolumn{2}{|c|}{ Effect }} & \multirow{2}{*}{$\begin{array}{l}\text { Alleles No. } \\
\text { (Frequency) }\end{array}$} \\
\hline Nucleotide change & Amino acid change & & & & \\
\hline c. $-259 \mathrm{C}>\mathrm{T}^{\mathrm{a}, \mathrm{b}}$ & - & Basal promoter & Pathogenic & $\left(\mathrm{T}^{\mathrm{c}}\right)$ & $1(0.2)$ \\
\hline c. $-23+1 \mathrm{G}>\mathrm{A}$ & - & Donor splice site & Pathogenic & $\left(\mathrm{T}^{\mathrm{c}}\right)$ & $2(0.4)$ \\
\hline c. $-22-12 \mathrm{C}>\mathrm{T}$ & - & Intron & Polymorphism & $\left(\mathrm{NT}^{\mathrm{c}}\right)$ & $1(0.2)$ \\
\hline c. $24 \mathrm{G}>\mathrm{A}$ & p.T8T & $\mathrm{N}$-terminus & Novel & $(\mathrm{NT})$ & $1(0.2)$ \\
\hline c. $35 \mathrm{delG}$ & p.G12Vfs*2 & $\mathrm{N}$-terminus (frameshift) & Pathogenic & $(\mathrm{T})$ & $84(15.9)$ \\
\hline c. $71 \mathrm{G}>\mathrm{A}^{\mathrm{d}}$ & p.W24X & M1 (nonsense) & Pathogenic & (T) & $5(0.9)$ \\
\hline c. $101 \mathrm{~T}>\mathrm{C}$ & p.M34T & M1 & Controversial & (NT) & $7(1.3)$ \\
\hline c. $109 \mathrm{G}>\mathrm{A}$ & p.V37I & M1 & Pathogenic & $(\mathrm{NT})$ & $5(0.9)$ \\
\hline c. $139 \mathrm{G}>\mathrm{T}$ & p.E47X & E1 (nonsense) & Pathogenic & (T) & $3(0.6)$ \\
\hline c.167delT & p.L56Rfs*26 & E1 (frameshift) & Pathogenic & (T) & $1(0.2)$ \\
\hline c. $250 \mathrm{G}>\mathrm{A}$ & p.V84M & M2 & Pathogenic & $(\mathrm{NT})$ & $1(0.2)$ \\
\hline c. $269 \mathrm{~T}>\mathrm{C}$ & p.L90P & M2 & Pathogenic & (NT) & $1(0.2)$ \\
\hline c. $283 \mathrm{G}>\mathrm{A}$ & p.V95M & M2 & Pathogenic & NT & $2(0.4)$ \\
\hline c.358_360delGAG & p.E120del & IC & Pathogenic & $\left(\mathrm{NT}^{\mathrm{e}}\right)$ & $3(0.6)$ \\
\hline c. $380 \mathrm{G}>\mathrm{A}$ & p.R127H & IC & Controversial & (NT) & $6(1.1)$ \\
\hline c. $457 \mathrm{G}>\mathrm{A}$ & p.V153I & M3 & Controversial & (NT) & $1(0.2)$ \\
\hline c. $468 \mathrm{G}>\mathrm{A}$ & p.G160S & $\mathrm{E} 2$ & Unclear & $(\mathrm{NT})$ & $1(0.2)$ \\
\hline c. $487 \mathrm{~A}>\mathrm{C}^{\mathrm{a}}$ & p.M163L & E2 & Pathogenic & $(\mathrm{T})$ & $1(0.2)$ \\
\hline c. $516 \mathrm{G}>\mathrm{A}$ & p.W172X & E2 (nonsense) & Pathogenic & (T) & $3(0.6)$ \\
\hline c. $550 \mathrm{C}>\mathrm{G}$ & p.R184W & $\mathrm{E} 2$ & Pathogenic & $(\mathrm{NT})$ & $1(0.2)$ \\
\hline c. $617 \mathrm{~A}>\mathrm{G}$ & p.N206S & M4 & Pathogenic & $(\mathrm{NT})$ & $3(0.6)$ \\
\hline
\end{tabular}

E1-2 = extracellular domain 1 or 2; M1-4 = transmembrane domain 1, 2, 3, or 4; IC = intracellular domain (between M2 and M3); $\mathrm{T}=$ truncating mutation; $\mathrm{NT}=$ nontruncating mutation. ${ }^{a}$ Mutations identified for the first time in the Portuguese population; ${ }^{b}$ Mutation up to now private to one Portuguese family; ${ }^{c}$ noncoding variant; ${ }^{d}$ Found in this study only in patients of Gypsy or Indian ethnicity/ancestry; ${ }^{~}$ deletion of one nonterminal codon, thus considered to be a nontruncating mutation.

Twenty-seven out of $264(10.2 \%)$ probands harboured only one $G J B 2$ variant. Subsequent analysis revealed that the GJB6 deletion $\operatorname{del}(G J B 6-\mathrm{D} 13 \mathrm{~S} 1854)$ was present in two of those patients (one heterozygous for c.35delG plus one heterozygous for p.M34T), both with prelingual, profound HL. One other patient solely harboured the dominant p.M163L mutation which has been previously described (Matos et al, 2008).

\section{Discussion}

A wide spectrum of $G J B 2$ variants, mostly pathogenic, was observed in the cohort of 264 NSSHL Portuguese individuals included in this study. Some variants of unclear effect (insufficient published data to infer pathogenicity) or of controversial pathogenicity (contradictory published data regarding pathogenicity) were also identified.

The DFNB1 genotype explained the HL, or was a likely cause of the pathology, in $20.8 \%(55 / 264)$ of the cases. All but two of these cases (53/55), corresponding to $20.8 \%$ of all the patients analysed, were presumed to be due to the GJB2 genotype and thus considered as GJB2-related HL. For the remaining two patients (2/55) the HL could be explained by the presence of a coding $G J B 2$ mutation (c.35delG or c.Met34Thr) and the GJB6 $\operatorname{del}(G J B 6-\mathrm{D} 13 \mathrm{~S} 1854)$, both in heterozygosity. The GJB2-related cases also include the patient harbouring the above referred dominant p.M163L mutation (Matos et al, 2008). Noteworthy, the HL in three patients with one coding $G J B 2$ mutation was explained by the presence of a second $G J B 2$ mutation in the basal promoter (c.-259C $>\mathrm{T}$ ) or in the donor splice site (c. $-23+1 \mathrm{G}>\mathrm{A})$. To our knowledge, the c.-259C $>\mathrm{T}$ mutation is so far restricted to the Portuguese family here presented. This mutation was not found in 91 normal-hearing Portuguese individuals from the general population (Matos et al, 2011) and reporter gene assays have shown that the mutation greatly impairs the promoter function (Matos et al, 2007). The finding of GJB2 pathogenic mutations in the basal promoter and donor splice site highlights the relevance of screening those noncoding regions in addition to the coding region.

The deletion c.35delG was the predominant GJB2 mutation among GJB2-related HL cases, in accordance with other European, or of mainly European descent populations (Dalámon et al, 2010; Pandya et al, 2003; Roux et al, 2004). Individuals homozygous for the c.35delG mutation accounted for about $53 \%$ of the GJB2-related HL cases, and represented $10.6 \%$ of the total Portuguese NSSHL patients. This predominance had also been observed in a different study conducted on a small number $(n=53)$ of NSHL Portuguese patients (Nogueira et al, 2011), and in a sample of 100 Portuguese cochlear implanted children, in which GJB2 genotype was shown to correlate to better oral performance (Chora et al, 2011).

Interestingly, the dominant GJB2 mutation p.M163L, causing mild/moderate high-frequency HL (Matos et al, 2008), has meanwhile also been found in one Argentinean patient presenting with prelingual, profound NSSHL (Dalamón et al, 2010), suggesting that the severity of the HL due to the p.M163L mutation might be variable and/or progressive.

As regards the controversial but potentially pathogenic p.M34T (Feldmann et al, 2004; Snoeckx et al, 2005; Bicego et al, 2006; Pollak et al, 2007) and p.R127H (RamShankar et al, 2003; Tóth et al, 2004; Bicego et al, 2006; Matos et al, 2010) variants, they were identified in patients harbouring an accompanying GJB2 
Table 2. GJB2 genotypes of the 80 patients carrying GJB2 variants.

\begin{tabular}{|c|c|c|c|c|c|}
\hline GJB2 genotypes & Probands & $\begin{array}{c}\text { Frequency \% } \\
(n=264)\end{array}$ & \multicolumn{2}{|c|}{ HL better ear } & History \\
\hline \multicolumn{6}{|l|}{ Two variants } \\
\hline \multirow[t]{4}{*}[\mathrm{c}.35\mathrm{delG}]{$+[\mathrm{c} .35 \mathrm{delG}]$} & 28 & 10.6 & 6 & Moderate & $9 \mathrm{FC} ; 9 \mathrm{SC} ; 10 \mathrm{Un}$ \\
\hline & & & 5 & Severe & \\
\hline & & & 12 & Profound & \\
\hline & & & 5 & Unreported & \\
\hline \multirow[t]{3}{*}[\mathrm{c}.35\mathrm{delG}]{$+[\mathrm{p} . \mathrm{E} 47 \mathrm{X}]$} & 3 & 1.1 & 1 & Moderate & $1 \mathrm{FC} ; 2 \mathrm{Un}$ \\
\hline & & & 1 & Profound & \\
\hline & & & 1 & Unreported & \\
\hline \multirow[t]{2}{*}[\mathrm{c}.35\mathrm{delG}]{$+[\mathrm{p} . \mathrm{W} 172 \mathrm{X}]$} & 3 & 1.1 & 1 & Moderate & Un \\
\hline & & & 2 & Profound & $\mathrm{SC}$ \\
\hline \multirow[t]{2}{*}[\mathrm{c}.35\mathrm{delG}]{$+[\mathrm{p} . \mathrm{V} 37 \mathrm{I}]$} & 2 & 0.8 & 1 & Mild & Un \\
\hline & 1 & 0.4 & 1 & Moderate & $\mathrm{FC}$ \\
\hline$[\mathrm{c} .35 \mathrm{delG}]+[\mathrm{c} .-23+1 \mathrm{G}>\mathrm{A}]$ & 1 & 0.4 & & Profound & SC \\
\hline$[\mathrm{c} .35 \mathrm{delG}]+[\mathrm{p} . \mathrm{W} 24 \mathrm{X}]$ & 1 & 0.4 & & Moderate & SC \\
\hline [c.35delG]+[p.M34T] & 1 & 0.4 & & Unreported & $\mathrm{SC}$ \\
\hline$[\mathrm{c} .35 \mathrm{delG}]+[\mathrm{c} .167 \mathrm{delT}]$ & 1 & 0.4 & & Severe & FC \\
\hline$[\mathrm{c} .35 \mathrm{delG}]+[\mathrm{p} . \mathrm{L} 90 \mathrm{P}]$ & 1 & 0.4 & & Moderate & SC \\
\hline$[\mathrm{c} .35 \mathrm{delG}]+[\mathrm{p} . \mathrm{V} 95 \mathrm{M}]$ & 1 & 0.4 & & Profound & $\mathrm{SC}$ \\
\hline [c.35delG]+[p.E120del] & 1 & 0.4 & & Moderate & SC \\
\hline [c.35delG]+[p.N206S] & 1 & 0.4 & & Moderate & FC \\
\hline$[\mathrm{p} . \mathrm{W} 24 \mathrm{X}]+[\mathrm{p} . \mathrm{W} 24 \mathrm{X}]$ & 1 & 0.4 & & Moderate & $\mathrm{FC}$ \\
\hline$[\mathrm{p} \cdot \mathrm{W} 24 \mathrm{X}]+[\mathrm{p} \cdot \mathrm{R} 127 \mathrm{H}]$ & 1 & 0.4 & & Moderate & $\mathrm{FC}$ \\
\hline [p.M34T]+[p.V95M] & 1 & 0.4 & & Moderate & $\mathrm{FC}$ \\
\hline [p.V37I]+[p.R184W] & 1 & 0.4 & & Severe & SC \\
\hline [p.V37I] + [p.N206S] & 1 & 0.4 & & Severe & SC \\
\hline$[\mathrm{p} . \mathrm{V} 84 \mathrm{M}]+[\mathrm{c} .-259 \mathrm{C}>\mathrm{T}]$ & 1 & 0.4 & & Profound & FC \\
\hline [p.E120del]+[p.E120del] & 1 & 0.4 & & Moderate & SC \\
\hline$[\mathrm{p} . \mathrm{R} 127 \mathrm{H}]+[\mathrm{c} .-23+1 \mathrm{G}>\mathrm{A}]$ & 1 & 0.4 & & Profound & SC \\
\hline$[\mathrm{p} . \mathrm{R} 127 \mathrm{H}]+[\mathrm{p} \cdot \mathrm{R} 127 \mathrm{H}]$ & 1 & 0.4 & & Unreported & FC \\
\hline Total & 53 & 20.1 & & & \\
\hline \multicolumn{6}{|l|}{ One variant } \\
\hline \multirow[t]{5}{*}[=]{$+[\mathrm{c} .35 \mathrm{delG}]$} & 12 & 4.5 & 1 & Mild & $4 \mathrm{FC} ; 5 \mathrm{SC} ; 3 \mathrm{Un}$ \\
\hline & & & 3 & Moderate & \\
\hline & & & 3 & Severe & \\
\hline & & & 3 & Profound & \\
\hline & & & 2 & Unreported & \\
\hline \multirow[t]{4}{*}[=]{$+[\mathrm{p} \cdot \mathrm{M} 34 \mathrm{~T}]$} & 5 & 1.9 & 1 & Moderate & $4 \mathrm{FC} ; 1 \mathrm{Un}$ \\
\hline & & & 1 & Severe & \\
\hline & & & 2 & Profound & \\
\hline & & & 1 & Unreported & \\
\hline$[=]+[p \cdot R 127 H]$ & 2 & 0.8 & 2 & Moderate & $1 \mathrm{FC} ; 1 \mathrm{SC}$ \\
\hline$[=]+[\mathrm{c} .-22-12 \mathrm{C}>\mathrm{T}]$ & 1 & 0.4 & & Severe & Un \\
\hline$[=]+[\mathrm{p} \cdot \mathrm{T} 8 \mathrm{~T}]$ & 1 & 0.4 & & Unreported & \\
\hline$[=]+[\mathrm{p} . \mathrm{W} 24 \mathrm{X}]$ & 1 & 0.4 & & Severe & \\
\hline$[=]+[\mathrm{p} . \mathrm{V} 37 \mathrm{I}]$ & 1 & 0.4 & & Profound & \\
\hline$[=]+[p . V 153 \mathrm{I}]$ & 1 & 0.4 & & Mild & \\
\hline$[=]+[\mathrm{G} 160 \mathrm{~S}]$ & 1 & 0.4 & & Moderate & \\
\hline$[\mathrm{p} \cdot \mathrm{M} 163 \mathrm{~L}]+[=]$ & 1 & 0.4 & & Mild & \\
\hline$[=]+[p \cdot N 206 S]$ & 1 & 0.4 & & Moderate & \\
\hline Total & 27 & 10.2 & & & \\
\hline
\end{tabular}

$\mathrm{FC}=$ Familial case $; \mathrm{SC}=$ Sporadic case $; \mathrm{Un}=$ Unreported; Symbols: $[=]$ wild type allele.

variant or the del(GJB6-D13S1854) deletion. Those genotypes were here considered to be the likely cause of the HL, with some reservations regarding the only p.R127H homozygous patient (negative for the GJB6 deletions). Since other hearing-impaired relatives of this patient were not available for study, we cannot know whether the p.R127H homozygous genotype is segregating with HL in the family.
The unclear p.V153I (RamShankar et al, 2003; Meşe et al, 2004; Snoeckx et al, 2005; Guerci et al, 2007) and p.G160S (Janecke et al, 2002; Snoeckx et al, 2005) were identified in heterozygosity in two of our patients, respectively. No inference regarding the relation of their GJB2 genotype with the HL could be made.

In which concerns genotype-phenotype correlation, truncating $(\mathrm{T})$ mutations are usually associated with a greater degree of HL than 
nontruncating (NT) mutations (Cryns et al, 2004; Putcha et al, 2007; Snoeckx et al, 2005). However, variability in the degree of the hearing loss in T/T genotypes has been noticed, and is well exemplified by the significant intra- and inter-familial variation, ranging from mild to profound impairment, observed in c.35delG homozygotes (Cryns et al, 2004; Murgia et al, 1999). In the present study, the majority $(n=17 / 23)$ of homozygotes for c.35delG with a reported phenotype had severe or profound HL, as expected.

As opposed to T/T GJB2 genotypes, NT/NT GJB2 genotypes appear to be often associated with mild or moderate HL (Putcha et al, 2007; Snoeckx et al, 2005). When considering NT/NT genotypes including at least one p.M34T or p.V37I allele, it was observed that they are usually, but not always, associated with less severe HL (Snoeckx et al, 2005). One patient of this study, with genotype [p.M34T] + [p.V95M], presented indeed with moderate HL. Two sporadic cases, compound heterozygous for $\mathrm{p}$.V37I plus one of two other NT mutations, p.R184W and p.N206S, however presented with severe HL, thus supporting previous observations (Snoeckx et al, 2005).

Regarding T/NT GJB2 genotypes, the variability on HL degree seems to depend on the NT mutation, at least when the T mutation is c.35delG (an early frameshift mutation). The two patients who were compound heterozygous for the p.V37I and c.35delG displayed mild and moderate HL, respectively, which is in accordance with the phenotypes previously found associated with this compound genotype by Cryns and co-workers (Cryns et al, 2004). The association of the $[\mathrm{c} .35 \mathrm{delG}]+[\mathrm{p} . \mathrm{V} 37 \mathrm{I}]$ genotype with less severe HL phenotypes was corroborated by other studies (Snoeckx et al, 2005; Pollak et al, 2007). One other T/NT GJB2 genotype, [c.35delG]+[p.L90P], is most commonly associated with mild or moderate HL (Cryns et al, 2004; Snoeckx et al, 2005; Pollak et al, 2007). Our patient presenting this genotype had a moderate hearing impairment. As regards the genotype [c.35delG] + [p.N206S], it apparently follows the same trend as the $[\mathrm{c} .35 \mathrm{delG}]+[\mathrm{p} . \mathrm{L} 90 \mathrm{P}]$ genotype (Snoeckx et al, 2005; Marlin et al, 2005). The [c.35delG]+[p.N206S] patient reported here presented with moderate HL. Finally, the [c.35delG]+[p.V95M] genotype, found here in two patients with severe HL, effectively appears to be more often associated with severe to profound HL (Cryns et al, 2004; Snoeckx et al, 2005) than with less severe HL (Cheng et al, 2005).

In general, our data meet the view that the severity of GJB2-related HL can be correlated with specific mutation combinations (Cryns et al, 2004; Snoeckx et al, 2005). Variation in the phenotype for a given genotype would likely be dependent on more than one major modifier gene, as suggested by the study of Hilgert and co-workers (Hilgert et al, 2009), as well as on environmental factors.

In conclusion, GJB2 mutations are a major cause of NSSHL in the Portuguese population, c.35delG being the predominant mutation, and each of the 19 other pathogenic/controversial variants occurring at much lower frequencies. Screening for the GJB2 donor splice site and basal promoter, and for the two common GJB6 deletions, allowed the elucidation of the HL etiology in some of the cases with only one coding mutation identified. Therefore, such screening, in patients harbouring only one coding mutation, is advisable and should be performed.

Overall, more than one in five of the Portuguese patients have been diagnosed as having DFNB1-related NSSHL. Analysis of GJB2 and GJB6 may thus represent a valuable indicator for clinicians, as regards therapeutical and rehabilitation options, as well as for genetic counselors of Portuguese patients and their families.
In fact, the current clinical assessment of hearing-impaired children/patients includes regular and sometimes invasive clinical investigations due to the possibility of the occurrence of dysfunction in other organs (syndromic HL). A conclusive genetic diagnosis can avoid these follow-ups, leading to a significant reduction of clinical investigations and inherent costs. Furthermore, the higher oral performance scores above referred, obtained in Portuguese cochlear implanted patients with DFNB1-associated deafness, show that individuals with this genetic etiology are good candidates for cochlear implantation, which represents an important prognostic tool.

\section{Acknowledgements}

The authors would like to thank the patients and their families for their collaboration to this investigation.

Declaration of interest: The authors report no declarations of interest. This study was supported by the Fundação para a Ciência e a Tecnologia POCTI/ESP/42078/2001, SFRH/BD/19988/2004, RIPD/SAU-ESP/63720/2005, and by the Secretariado Nacional de Reabilitação e Integração das Pessoas com Deficiência (Program CITE IV). Note that Maria do Céu Correia is presently retired.

\section{References}

Alford R.L. 2011. Nonsyndromic hereditary hearing loss. In: R.L. Alford \& V.R. Sutton (eds.), Medical Genetics in the Clinical Practice of ORL. Adv Otorhinolaryngol. Basel: Karger, vol. 70, pp. 37-42.

Álvarez A., del Castillo I., Villamar M., Aguirre L.A., González-Neira A. et al. 2005. High prevalence of the W24X mutation in the gene encoding connexin-26 (GJB2) in Spanish Romani (gypsies) with autosomal recessive non-syndromic hearing loss. Am J Med Genet A, 137A, 255-258.

Bicego M., Beltramello M., Melchionda S., Carella M., Piazza V. et al. 2006. Pathogenetic role of the deafness-related M34T mutation of Cx26. Hum Mol Genet, 15, 2569-2587.

Cheng X., Li L., Brashears S., Morlet T., Ng S.S. et al. 2005. Connexin 26 variants and auditory neuropathy/dys-synchrony among children in schools for the deaf. Am J Med Genet A, 139, 13-18.

Chora J.R., Matos T.D., Martins J.H., Alves M.C., Andrade S.M. et al. 2010. DFNB1-associated deafness in Portuguese cochlear implant users: Prevalence and impact on oral outcome. Int J Pediatr Otorhinolaryngol, 74, 1135-1139.

Cryns K., Orzan E., Murgia A., Huygen P., Moreno F. et al. 2004. A genotype-phenotype correlation for GJB2 (connexin 26) deafness. J Med Genet, 41, 147-154.

Dalamón V., Lotersztein V., Béhèran A., Lipovsek M., Diamante F. et al. 2010. GJB2 and GJB6 genes: molecular study and identification of novel GJB2 mutations in the hearing-impaired Argentinean population. Audiol Neurootol, 15, 194-202.

del Castillo F.J., Rodriguez-Ballesteros M., Alvarez A., Hutchin T., Leonardi E. et al. 2005. A novel deletion involving the connexin-30 gene, del(GJB6-d13s1854), found in trans with mutations in the GJB2 gene (connexin-26) in subjects with DFNB1 non-syndromic hearing impairment. J Med Genet, 42, 588-594.

Denoyelle F., Marlin S., Weil D., Moatti L., Chauvin P. et al. 1999. Clinical features of the prevalent form of childhood deafness, DFNB1, due to a connexin-26 gene defect: Implications for genetic counselling. Lancet, 353, 1298-1303.

Feldmann D., Denoyelle F., Loundon N., Weil D., Garabedian E.-N. et al. 2004. Clinical evidence of the nonpathogenic nature of the M34T variant in the connexin 26 gene. Eur J Hum Genet, 12, 279-284.

Guerci V.I., Grasso D.L., Morgutti M., Amoroso A., D’Andrea P. et al. 2007. Connexin 26 gene: Defining the role of the V153I mutation. Audiol Med, 5, 200-206. 
Hilgert N., Huentelman M.J., Thorburn A.Q., Fransen E., Dieltjens N. et al. 2009. Phenotypic variability of patients homozygous for the GJB2 mutation $35 \mathrm{delG}$ cannot be explained by the influence of one major modifier gene. Eur J Hum Genet, 17, 517-524.

Hilgert N., Smith R.J. \& Van Camp G. 2009. Forty-six genes causing nonsyndromic hearing impairment: Which ones should be analysed in DNA diagnostics? Mutat Res, 681, 189-196.

Janecke A.R., Hirst-Stadlmann A., Gunther B., Utermann B., Muller T. et al. 2002. Progressive hearing loss, and recurrent sudden sensorineural hearing loss associated with GJB2 mutations: Phenotypic spectrum and frequencies of GJB2 mutations in Austria. Hum Genet, $111,145-153$.

Kenneson A., Van Naarden Braun K. \& Boyle C. 2002. GJB2 (connexin 26) variants and nonsyndromic sensorineural hearing loss: a HuGE review. Genet Med, 4, 258-274.

Lerer I., Sagi M., Ben-Neriah Z., Wang T., Levi H. et al. 2001. A deletion mutation in GJB6 cooperating with a GJB2 mutation in trans in non-syndromic deafness: A novel founder mutation in Ashkenazi Jews. Hum Mutat, 18, 460.

Mani R.S., Ganapathy A., Jalvi R., Srikumari Srisailapathy C.R., Malhotra V. et al. 2009. Functional consequences of novel connexin 26 mutations associated with hereditary hearing loss. Eur J Hum Genet, $17,502-509$.

Marlin S., Feldmann D., Blons H., Loundon N., Rouillon I. et al. 2005. GJB2 and GJB6 mutations: Genotypic and phenotypic correlations in a large cohort of hearing-impaired patients. Arch Otolaryngol Head Neck Surg, 131, 481-487.

Matos T.D., Caria H., Simões-Teixeira H., Aasen T., Dias O. et al. 2008. A novel M163L mutation in connexin 26 causing cell death and associated with autosomal dominant hearing loss. Hear Res, 240, 87-92.

Matos T.D., Caria H., Simões-Teixeira H., Aasen T., Nickel R. et al. 2007. A novel hearing-loss-related mutation occurring in the GJB2 basal promoter. J Med Genet, 44, 721-725.

Matos T.D., Simões-Teixeira H., Caria H., Cascão R., Rosa H. et al. 2011. Assessing noncoding sequence variants of GJB2 for hearing loss association. Genet Res Int, 2011, Article ID 827469.

Matos T.D., Simões-Teixeira H., Caria H., Rosa H., O’Neill A. et al. 2010. The controversial p.Arg127His mutation in GJB2: Report on three Portuguese hearing loss family cases. Genet Test Mol Biomarkers, 14, 141-144.

Meșe G., Londin E., Mui R., Brink P.R. \& White T.W. 2004. Altered gating properties of functional $\mathrm{Cx} 26$ mutants associated with recessive nonsyndromic hearing loss. Hum Genet, 115, 191-199.

Minárik G., Ferák V., Feráková E., Ficek A., Poláková H. et al. 2003. High frequency of GJB2 mutation W24X among Slovak Romany (Gypsy) patients with non-syndromic hearing loss (NSHL). Gen Physiol Biophys, 22, 549-556.

Murgia A., Orzan E., Polli R., Martella M., Vinanzi C. et al. 1999. Cx26 deafness: mutation analysis and clinical variability. J Med Genet, 36, 829-832.
Nogueira C., Coutinho M., Pereira C., Tessa A., Santorelli F.M. et al. 2011. Molecular investigation of pediatric Portuguese patients with sensorineural hearing loss. Genet Res Int, 2011, Article ID 587602.

Pallares-Ruiz N., Blanchet P., Mondain M., Claustres M. \& Roux A-F. 2002. A large deletion including most of GJB6 in recessive non-syndromic deafness: A digenic effect? Eur J Hum Genet, 10, 72-76.

Pandya A., Arnos K.S., Xia X.J., Welch K.O., Blanton S.H. et al. 2003. Frequency and distribution of GJB2 (connexin 26) and GJB6 (connexin 30) mutations in a large North American repository of deaf probands. Genet Med, 5, 295-303.

Pollak A., Skórka A., Mueller-Malesi ska M., Kostrzewa G., Kisiel B. et al. 2007. M34T and V37I mutations in GJB2 associated hearing impairment: Evidence for pathogenicity and reduced penetrance. Am J Med Genet A, 143A, 2534-2543.

Putcha G.V., Bejjani B.A., Bleoo S., Booker J.K., Carey J.C. et al. 2007. A multicenter study of the frequency and distribution of GJB2 and GJB6 mutations in a large North American cohort. Genet Med, 9, 413-426.

RamShankar M., Girirajan S., Dagan O., Ravi S., Jalvi R. et al. 2003. Contribution of connexin26 (GJB2) mutations and founder effect to non-syndromic hearing loss in India. J Med Genet, 40, e68.

Roux A-F., Pallares-Ruiz N., Vielle A., Faugère V., Templin C. et al. 2004. Molecular epidemiology of DFNB1 deafness in France. BMC Med Genet, 5,5 .

Scott D.A., Kraft M.L., Carmi R., Ramesh A., Elbedour K. et al. 1998. Identification of mutations in the connexin 26 gene that cause autosomal recessive nonsyndromic hearing loss. Hum Mutat, 11, 387-394. FASEB J, 18, 860-862.

Smith R.J., Shearer A.E., Hildebrand M.S. \& Van Camp G. 2013. Deafness and Hereditary Hearing Loss Overview. In: R.A. Pagon, T.D. Bird, C.R. Dolan, K. Stephens, M.P. Adam (eds.), GeneReviews ${ }^{T M}$ [internet]. Seattle (WA): University of Washington, Seattle.

Smith R.J., Sheffield A.M. \& Van Camp G. 2012. Nonsyndromic Hearing Loss and Deafness, DFNA3. In: R.A. Pagon, T.D. Bird, C.R. Dolan, K. Stephens, M.P. Adam (eds.), GeneReviews ${ }^{T M}$ [internet]. Seattle (WA): University of Washington, Seattle.

Smith R.J. \& Van Camp G. 2011. Nonsyndromic Hearing Loss and Deafness, DFNB1. In: R.A. Pagon, T.D. Bird, C.R. Dolan, K. Stephens, M.P. Adam (eds.), GeneReviews ${ }^{T M}$ [internet]. Seattle (WA): University of Washington, Seattle.

Snoeckx R.L., Huygen P.L.M., Feldmann D., Marlin S., Denoyelle F. et al. 2005. GJB2 mutations and degree of hearing loss: A multicenter study. Am J Hum Genet, 77, 945-957.

Stenson P.D., Mort M., Ball E.V., Howells K., Phillips A.D. et al. 2009. The human gene mutation database: 2008 update. Genome Med, 1, 13.

Storm K., Willocx S., Flothmann K. \& Van Camp G. 1999. Determination of the carrier frequency of the common GJB2 (connexin-26) 35delG mutation in the Belgian population using an easy and reliable screening method. Hum Mutat, 14, 263-266. Hum Genet, 111, 190-197.

Tóth T., Kupka S., Haack B., Riemann K., Braun S. et al. 2004. GJB2 mutations in patients with non-syndromic hearing loss from northeastern Hungary. Hum Mutat, 23, 631-632. 
Copyright of International Journal of Audiology is the property of Taylor \& Francis Ltd and its content may not be copied or emailed to multiple sites or posted to a listserv without the copyright holder's express written permission. However, users may print, download, or email articles for individual use. 